\title{
EMISSION AND PERFORMANCE CHARACTERISTICS OF COMPRESSED IGNITION ENGINE FUELED WITH HYDROGEN AND DIESEL
}

\author{
Y. DILIPKUMAR ${ }^{1} *$ \& DR. M. YOHAN ${ }^{2}$ \\ ${ }^{1}$ Research Scholar, Department Mechanical Engineering, Jawaharlal Nehru Technological University, Anantapuramu, \\ Andhra Pradesh, India \\ ${ }_{2}^{2}$ Professor, Department Mechanical Engineering, Jawaharlal Nehru Technological University, Anantapuramu,
} Andhra Pradesh, India

\begin{abstract}
The internal combustion (IC) engines have recently become a key and important bit of our present day life. Hydrogen is an inexhaustible and clean-consuming fuel it gives ascends to some unwanted burning issues in an engine activity, for example, Misfire, premature combustion, pinking and quick amount of pressure rise in combustion chamber. It has been tentatively assessed that the Timed Manifold Induction (TMI) procedure plays a prevailing work in acquiring smooth engine operation. The variation of loads and range of pressures the Emissions of $\mathrm{CO}, \mathrm{CO}_{2}, \mathrm{HC}, \mathrm{NO}_{\mathrm{X}}$, and $\mathrm{O}_{2}$ qualities are analyzed for a Compressed Ignition engine working on Diesel and Hydrogen in dual fuel mode. In this, experimentation of engine has been tried at particular flow rate of diesel and hydrogen at constant speed and at steady pressure proportion. With the increased load and fraction of Hydrogen $\left(\mathrm{H}_{2}\right)$ being introduced into the engine by $10 \%$, 20\%, 30\%, 40\% and half of the total charge, With expanding load and fraction of Hydrogen $\left(\mathrm{H}_{2}\right)$ introduction into the engine by $10 \%, 20 \%, 30 \%, 40 \%$ and $50 \%$ of absolute charge there is a significant decreases in smoke emissions and an astounding increase in nitrogen oxides. Totally unburned hydrocarbons are seen with the expansion of hydrogen content in spite of the way that $\mathrm{CO}_{2}$ and $\mathrm{CO}$ gaseous releases diminished extensively. Because of lower carbon in the Diesel-Hydrogen, carbon monoxide diminishes with $\mathrm{H}_{2}$ expansion

KEYWORDS: IC Engine, Hydrogen, Timed Manifold Induction (TMI) Technique, Load \& Emissions
\end{abstract}

Received: Jun 09, 2020; Accepted: Jun 29, 2020; Published: Jul 20, 2020; Paper Id.: IJMPERDJUN2020397

\section{INTRODUCTION}

Hydrogen has unusually low start vitality allowing lean blends to be ignited by hydrogen engines and ensuring prompt ignition. Hydrogen gas in diesel engines can deliver engine execution development and lessen gas outflows, mainly oxides of nitrogen, incomplete hydrocarbons, and carbon dioxide. Then again, there are different analysts who guaranteed then the utilization of hydrogen expands exhaust gas emissions, especially nitrogen oxides. The utilization of applying hydrogen gas to diesel engine greatly decreases fuel consumption, lowers fuel costs, increases mileage and eliminates pollution. T S Hora and A K. Agarwal et al [1] have led to trail investigation of the impact of pressure of hydrogen improved Natural gas with parameters for engine execution, combustion and emission. In their experimentation, BTE, BSEC, and BSFC improved with a load just an addition of hydrogen to CNG.-Exhaust Gas Temperature (EGT) was seen to be lower for Hydrogen Enriched Compressed Natural Gas (HECNG) blends. Ignition qualities, for example pressure in the cylinder, amount of pressure rise, and the rate of heat release were additionally improved with HECNG blends. Combustion chamber pressure was higher at higher loads and it is moving towards $\mathrm{TDC} . \mathrm{CO}_{2}$ and $\mathrm{NOx}$ emission levels increased with a break mean effective pressure 
of a given fuel, while $\mathrm{CO}$ and $\mathrm{HC}$ were decreased. Anyway, with the expansion of hydrogen, $\mathrm{CO}_{2}, \mathrm{CO}$ and $\mathrm{HC}$ outflows have been lowered whilst the NOx discharges have been boosted. Yasin Karago'z et al [2] tried by utilizing hydrogen as a fuel, an impact of $25 \%$ and $50 \%$ of hydrogen advancement on execution, out streams and consuming characteristics at full load and distinctive engine speeds were analyzed, they saw that Break thermal efficiency esteem diminishes by $3.3 \%$ $8.1 \%$ with a $25 \%$ hydrogen expansion and by $8.2 \%-15.5 \%$ with $50 \%$ of hydrogen expansion contrasted with a diesel fuel.. NOx discharges extended by $15.2 \%-39.6 \%$ with a $25 \%$ hydrogen augmentation and $68.6 \%-212.7 \%$ with an expansion of $50 \%$ hydrogen contrasted with a diesel. Rajasekher S Hosmath et al [3] performed and analyzed a test on a Diesel and BioDiesel-Hydrogen fuel mixes in an altered diesel engine worked with a Dual Fuel mode, they saw that enhancements in thermal performance with the extension of hydrogen vitality proportion $20 \%$ of combustion is uncontrolled at high levels of hydrogen infusion into the inlet manifold, which consequently reduces thermal efficiency. Yang Z Chu C. et al [4] contemplated the effect of including $\mathrm{H} 2$ the burning and outflow characteristics of the Cummins ISM370 diesel engine. The chamber weight and pace of warmth discharge were tried with an expansion of $6 \% \mathrm{H} 2$ to the motor under a heap of $70 \%$. For this, AVL, FIRE programming was utilized with the expansion of $6 \% \mathrm{H} 2$ to fabricate a numerical engine model at 70 percent load._The results of the reproduction and the exploratory outcomes have been thought of, and the outcomes gave a decent consistency. Also, the rate of heat release, pressure, NOx emissions and particulate matter (PM) were reenacted at $70 \%$ load with the extension of $\mathrm{H} 2$ from $6 \%$ to $20 \%$. The effect of the presentation of different $\mathrm{H}_{2}$ levels on the engine's ignition and outflow characteristics was assessed by then. The engine was worked with hydrogen-diesel duel fuel system under lean consume conditions. The discharge and ignition investigation should be possible if there ought to be an occurrence attributable to the predominant rate of burning of hydrogen, the fume gas temperature was high at the perfect condition of infusion of hydrogen advancement. Yadav et al [5], Investigated emission and burning tests can be performed during the ideal infusion process of the revamped direct infusion, a four-stroke single-chamber, air-cooled, fixed hydrogenfilled Kirlosker engine, limited to $1500 \mathrm{rpm}$ and coupled to a $4.4 \mathrm{~kW}$ electrical generator. The timing of injections (18.5, 20, 21.5, 24.5, 27.50 Crank Angle) and the flow rate of hydrogen was differed (80, 120, 150 grams an hour) in order to discover the optimal conditions for optimizing hydrogen efficiency. The findings revealed that at 16.4 percent $\mathrm{H} 2$ or 120 grams per hour of stream rate with 200 Crank Angle infusion timing, the most important brake thermal efficiency and least specific fuel consumption was obtained. Owing to the increased rate of hydrogen combustion, the temperature of the exhaust gas was high when the hydrogen enrichment accident occurred. Fanous Christodoulou et al [6] have conducted a preliminary analysis of the individual hydrogen and nitrogen channels aligned with the inlet tubing. Packaged gas was mixed into the engine at fixation from 2 to $8 \%$ (v/v of the total confirmation charge) in $2 \%$ steps. They found that hydrogen augmentation reduces fumes and CO to the downside of low-speed, low-load NOx emissions, where NOx persists at the same level. Wu Hong-Wen et al [7] carried out an investigation of the burning qualities and discharges of hydrogen-diesel blends utilizing the vitality sharing innovation of the diesel engine. Chamber gas pressure, mass flow of air, the mass flow of fuel, and discharges were evaluated under various engine loads and 0\% -40\% EGR proportions balanced in hydrogen vitality proportions at various loads. The ignition qualities, for example, cyclic changes, HRR, BTE and SFC were settled. The results show that the coefficient of variation estimations, IMEP ranges from $0.9 \%$ to $2.8 \%$. The pace of lessening in the smoke releases is $37.6 \%$ and that in the NOx discharges is $59.5 \%$ for a $60 \%$ weight, $40 \%$ EGR extent, and $20 \%$ included hydrogen. Shahad, Haroun AK et al. [8] did an exploratory examination to consider the effect of Hydrogen Manifold Injection on the presentation of Compression Ignition Engines. Hydrogen was pumped into the inlet nozzle, and hydrogen expansion took place at the energy exchange point. This was discovered that the addition of hydrogen increases the combustion cycle as a result of unrivaled hydrogen burning properties in the conventional diesel study. In comparison, 
it was observed that $10 \%$ vitality replacement improves the engine thermal efficiency by about $40 \%$ and lessens the specific fuel usage by about $35 \%$, in spite of the fact that the volumetric efficiency has diminished by about $35 \%$. N. Saravanan et al. [9] conducted an experiment, and emission qualities were learned at various injection timings of Hydrogen from their analysis smoke emissions reduced 6.8 $\mathrm{BSN}$ to $2.3 \mathrm{BSN}, \mathrm{NO}_{\mathrm{x}}$ emissions decreased from 1806 to $888 \mathrm{PPM}$ and $\mathrm{CO}, \mathrm{CO}_{2}, \mathrm{HC}$ additionally reduced significantly. J M. Gomes Antunes et al.[10] depicted the improvement of a test set up for the testing of a diesel engine in the immediate infusion fuelled mode.The use of hydrogen direct infusion in a diesel engine gave a more force yield to weight proportion when contrasted and regular diesel fuelled activity with inaccurate $14 \%$ high peak power. The prompt infusion of hydrogen allows much better control of engine activity contrasted and port infusion in HCCI mode. Examinations of direct infusion of hydrogen with HCCI techniques for activity were done and reasoned that the prompt infusion of hydrogen offers the likelihood to control and cutoff over the unreasonable mechanical loads while this is in every way that really matters uncontrolled in the HCCI method of activity. They additionally saw that the reductions of NOx discharge level.

\section{EXPERIMENTAL METHODOLOGY}

The experiment was performed on a single cylinder, four stroke CI engine consenting to the Indian standard as seen in Figure 1. The engine was connected to an eddy current dynamometer and calibrated with a crank angle sensor to run the engine at a speed of $1500 \mathrm{rpm}$.Uncommon consideration is taken to keep the speed of the engine steady ( \pm 10rpm) during information procurement for each instance of engine activity at various load and diverse hydrogen enlistment procedures. Analyses were completed with hydrogen and diesel in duel fuel activity and the engine was worked with diesel, diesel and hydrogen mixes at a consistent speed of $1500 \mathrm{rpm}$ at loads of 0,2,4,6,8,10 and $12 \mathrm{~kg}$. The parameters of combustion, efficiency and emission have been studied and plotted at each loading condition The study was performed with diesel and the application of hydrogen to diesel in in different liters per minutes like 10\%, 20\%,30\%,40\%, and 50\% of the injections of Hydrogen at various IOP conditions. The engine is then changed to a duel fuel method of activity with hydrogen as the essential fuel and diesel as the pilot fuel under a similar working condition. To turn over the engine lift the decompress or lever on the engine and rotate the flywheel fast by the handles. When the flywheel achieves a constant speed then push decompress or lever down and continue for a couple of turns.In the current analysis, hydrogen was infused into the inlet manifold using the Timed Manifold Induction (TMI) technique, and diesel was used as the pilot fuel for ensuring the dual fuel operation. Set the IOP at 200,220,240 bar and compression ratio17, operate the engine at a consistent speed of 1500 rpm at 0,2,4,6,8,10 and $12 \mathrm{~kg}$ loads and noticed the estimations of $\mathrm{CO}, \mathrm{CO}_{2}, \mathrm{HC}, \mathrm{O} 2$, and $\mathrm{NO}_{\mathrm{x}}$ outflows with the assistance of exhaust gas analyzer as appeared in underneath figures. The Timed Manifold Induction (TMI) methodology will initiate the transport of fuel at the preparation place a few seconds after the initiate of the admission of the entry stroke in order to maintain a pre-cooling effect and thereby render pre-start sources unable.. In fact, it helps to stifle and degrade any residual combustion products that may be present in the compression area near TDC 

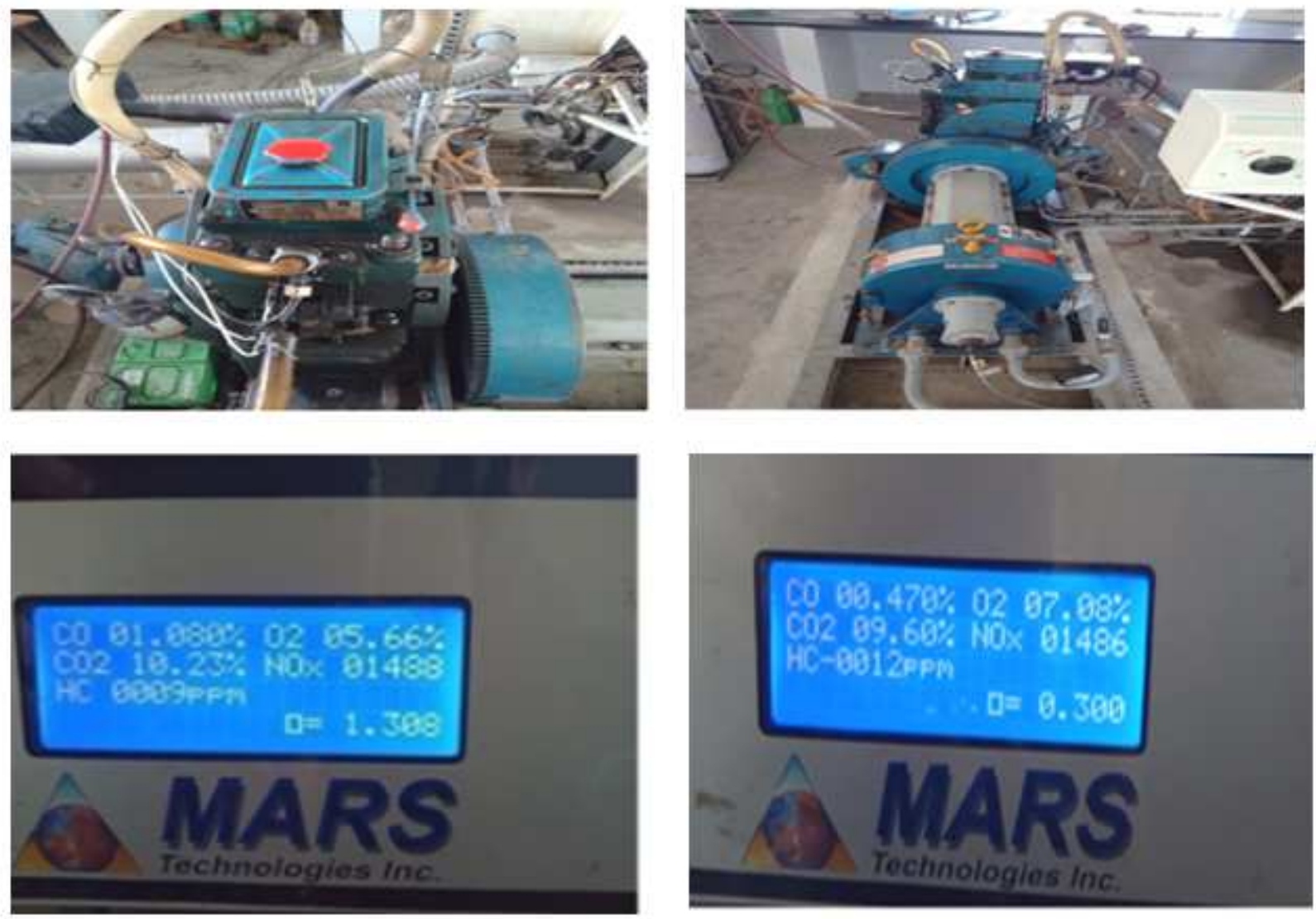

Figure 1: Four-stroke single cylinder CI Engine with dynamometer and exhaust gas analyzer

\section{RESULTS AND DISCUSSIONS}

Investigations were done at various loads for different rates of $\mathrm{H}_{2}$ included diesel for variable pressures.Figure. 2 shows the association between the load and $\mathrm{CO} \%$ for various pressures. From this calculation, it is found that the amount of carbon monoxide has reduced with an increase in the amount of hydrogen added. This might be a delayed consequence of the nonmonitoring of carbon particles in the hydrogen system

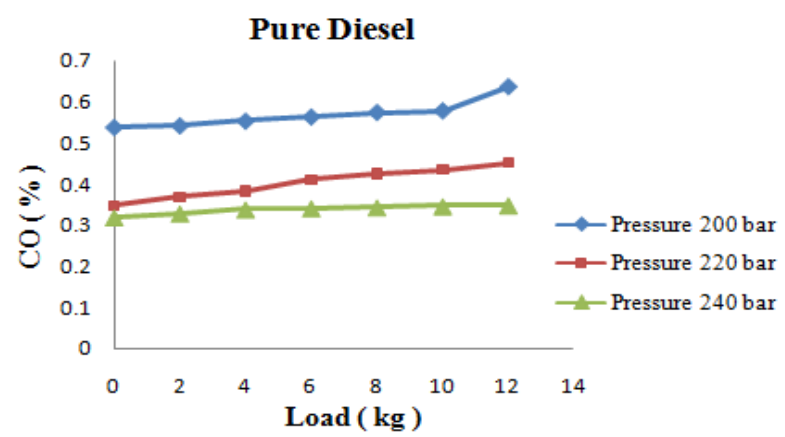

(a)

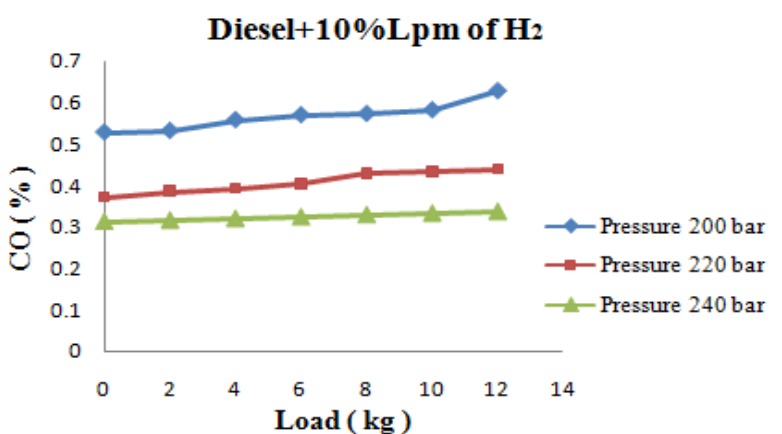

(b) 


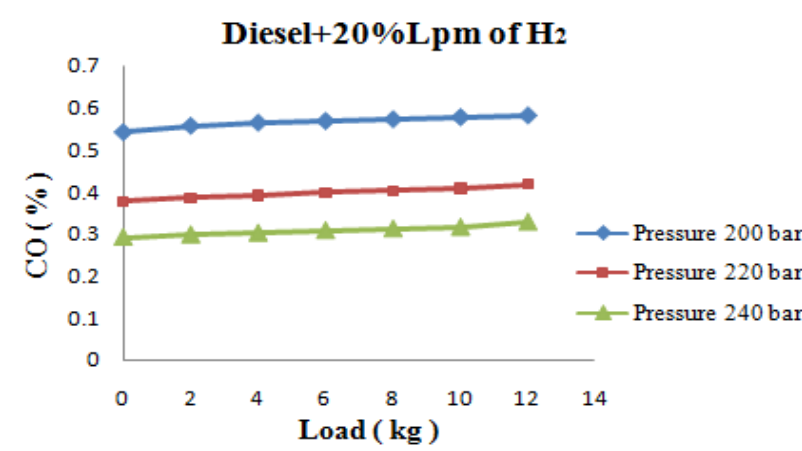

(c)

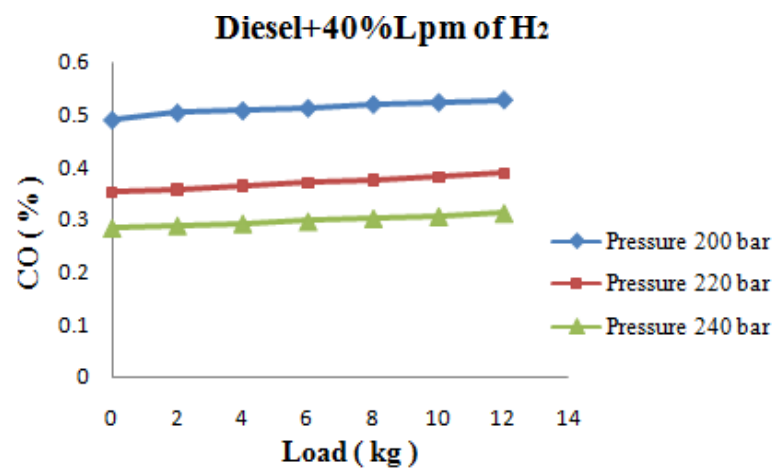

(e)

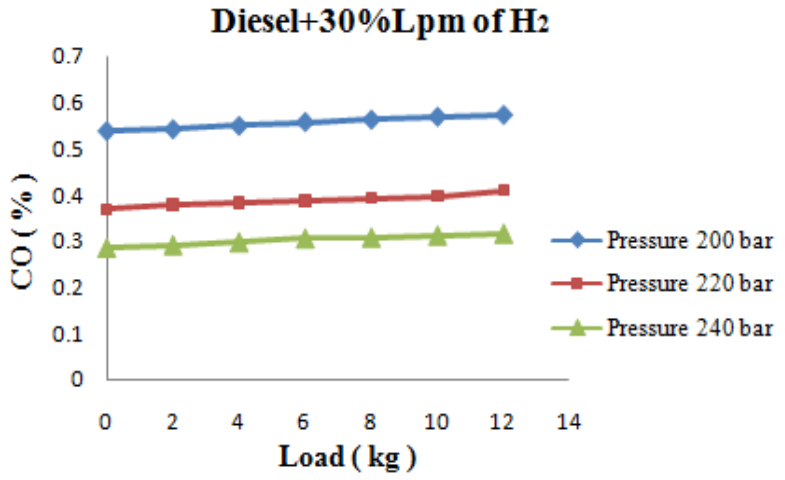

(d)

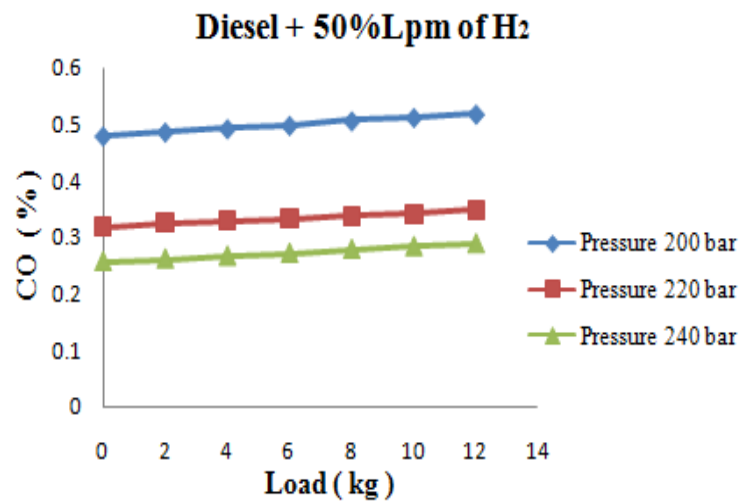

(f)

Figure 2: Relation between Load and CO \% for different $\mathrm{LPM}$ of $\mathrm{H}_{2}$ at Various Pressures.

Relationship among loads and $\mathrm{CO}_{2} \%$ with different pressures is as appeared in Figure.3. It is unquestionably seen from the figures that at most extreme load conditions, when the addition of hydrogen to diesel increases $\mathrm{CO}_{2} \%$ gets decreases. That may be due to the fact that the carbon particles found in the principle fuel and oxidized at a maximum cylinder temperature and the gas changed over into $\mathrm{CO}_{2}$.

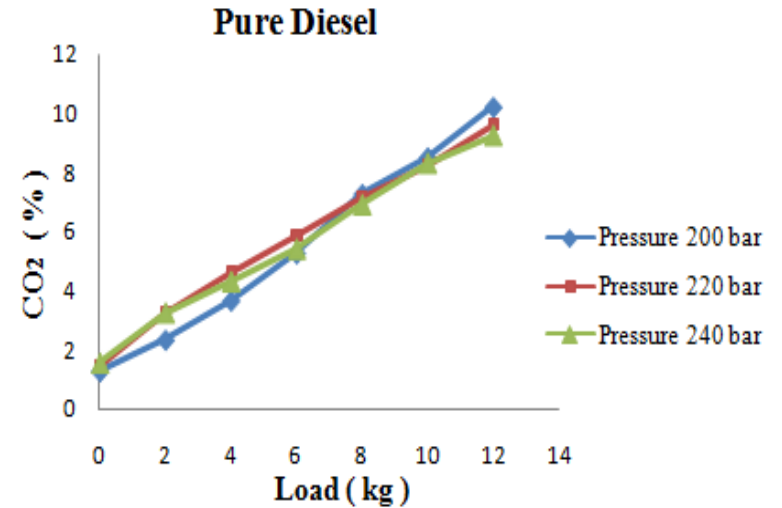

( a )

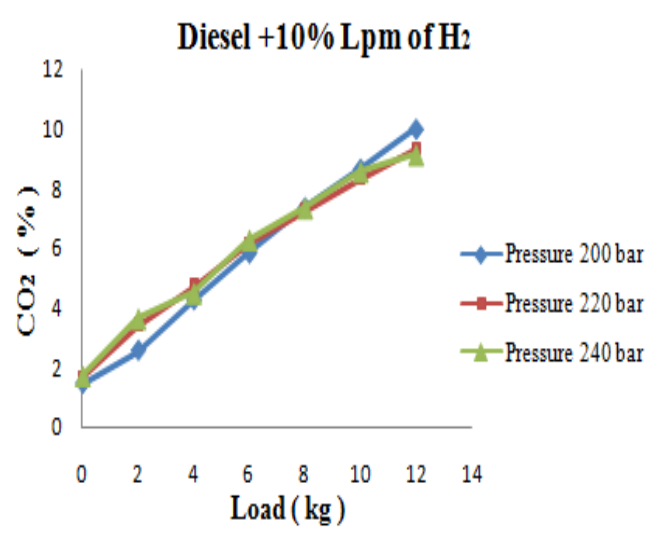

(b) 


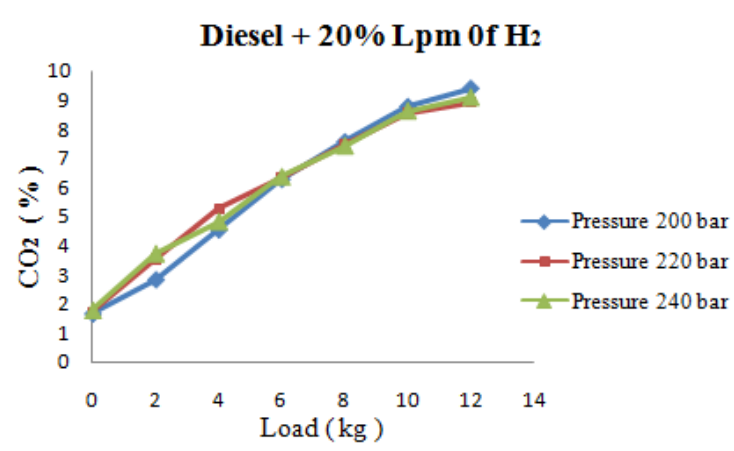

(c)

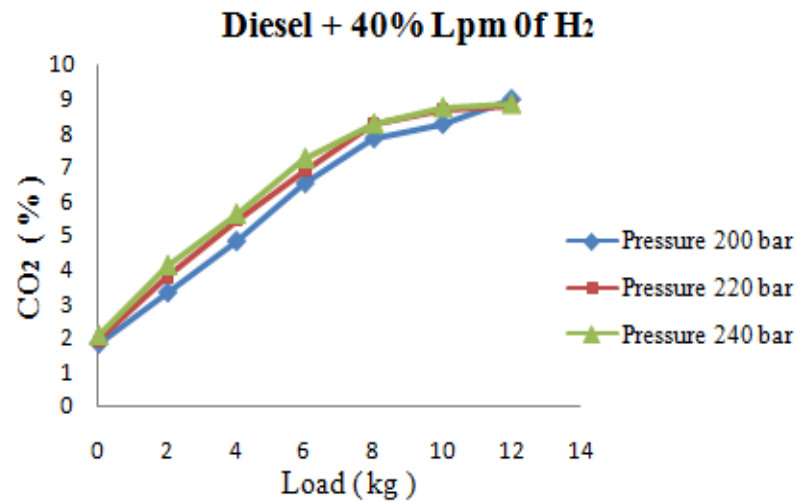

(e)

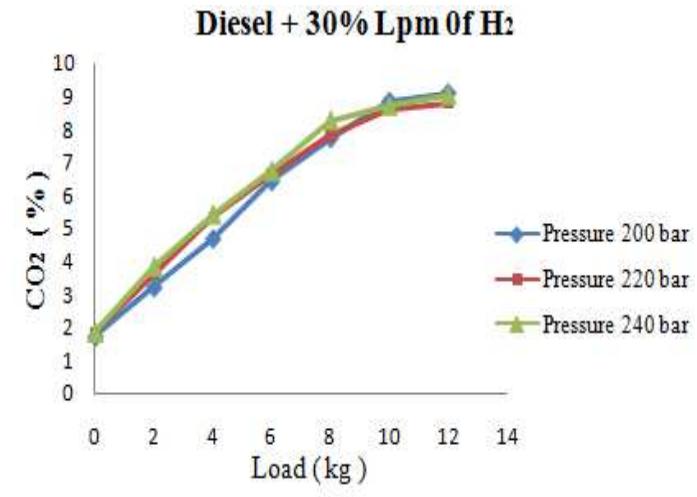

(d)

Diesel $+\mathbf{5 0} \% \mathrm{Lpm}$ of $\mathrm{H}_{2}$

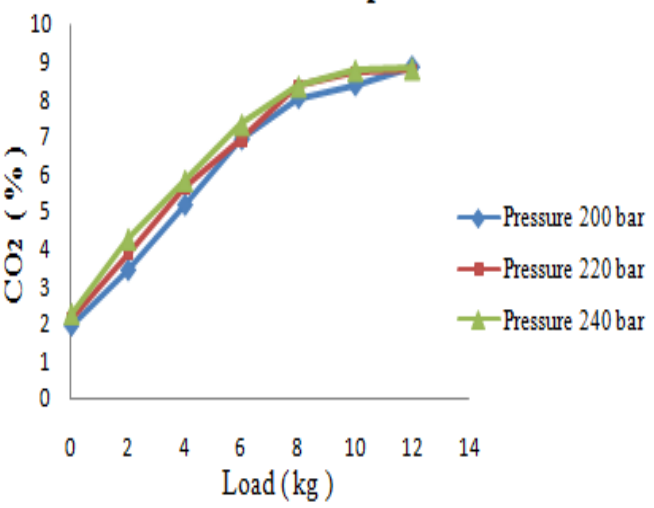

(f)

Figure 3: Relation between Load and $\mathrm{CO}_{2} \%$ for different $\mathrm{LPM}$ of $\mathrm{H}_{2}$ at Various Pressures

Figure.4 shows the association between the load and HC in PPM at variable pressures. From results it is seen that $\mathrm{HC}$ emissions decreased for increased hydrogen addition to the diesel.

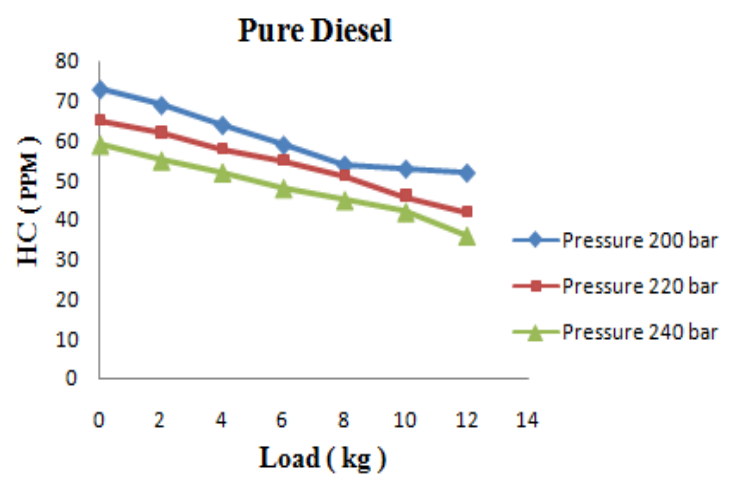

(a)

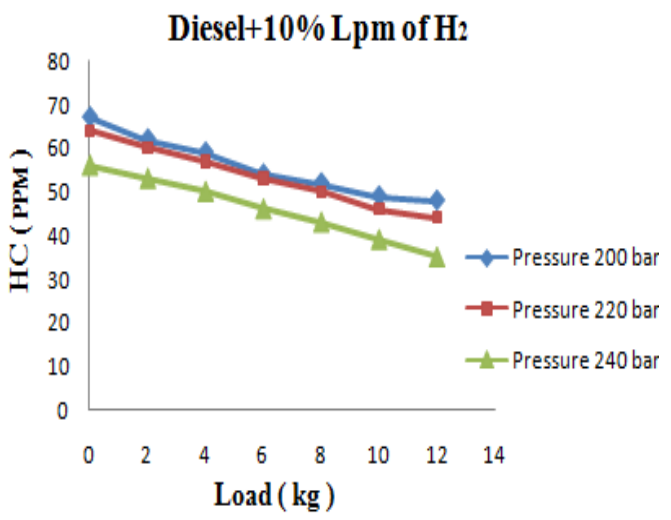

(b) 


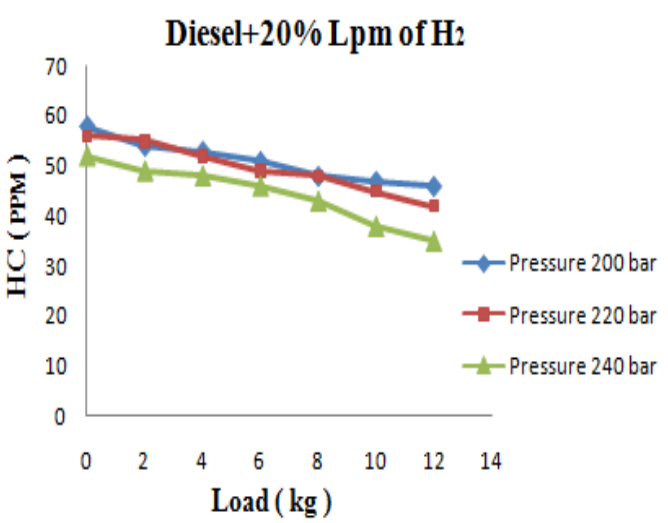

(c)

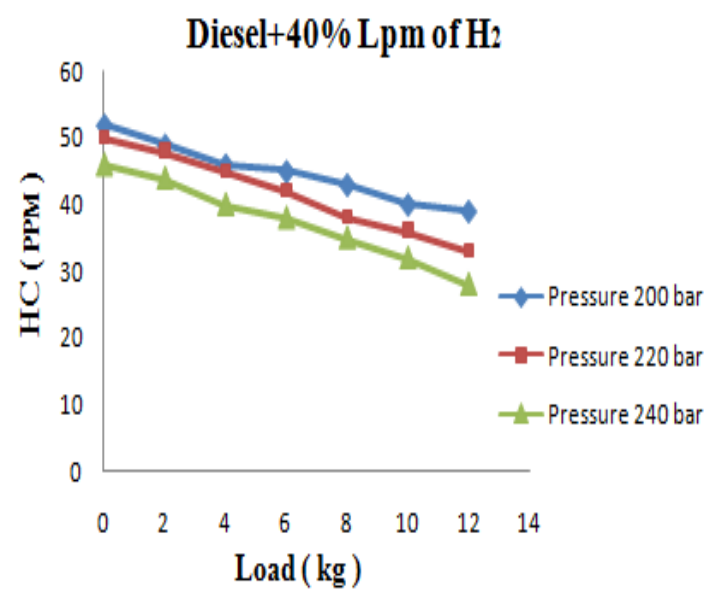

(e )

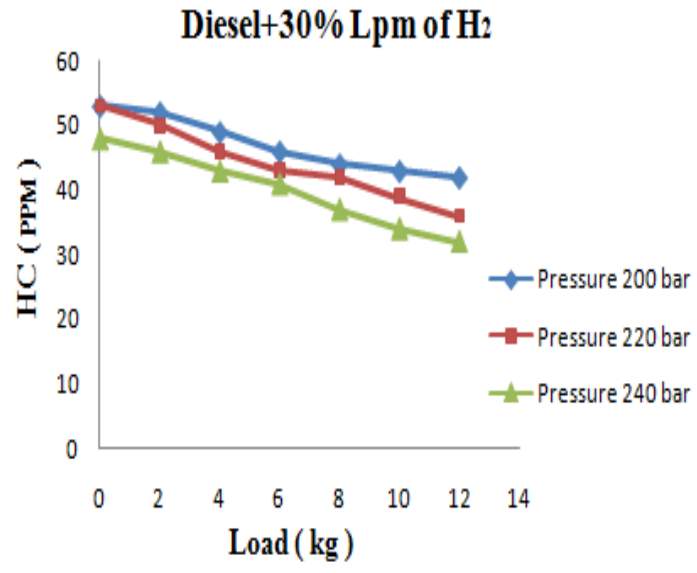

(d)

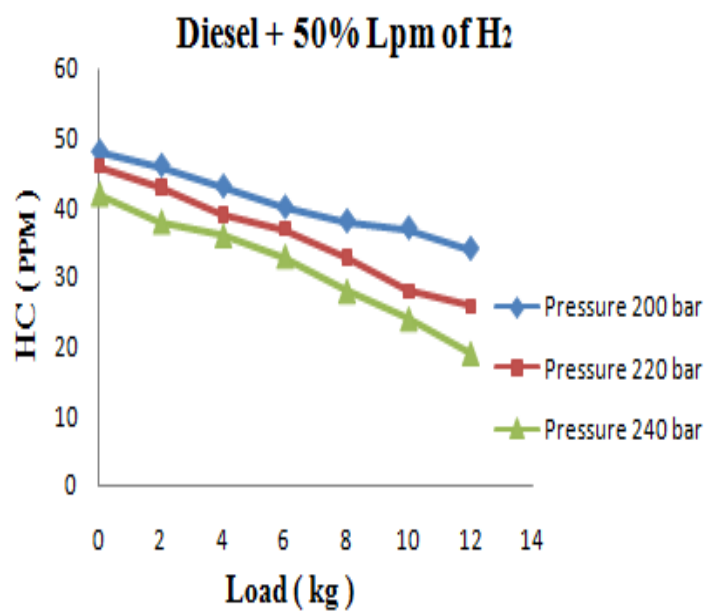

(f)

Figure 4: Relation between Load and HC in PPM for different LPM of $\mathrm{H}_{2}$ at Various Pressures

Figure.5 shows that Association among load and NOx in PPM for different pressure conditions. Figures reveal that, $\mathrm{NO}_{\mathrm{X}}$ discharges were seen as more extreme at full load conditions. The explanation of this one might be a higher convergence of $\mathrm{NO}_{\mathrm{X}}$ in the event of hydrogen enhancement because of peak burning temperature.

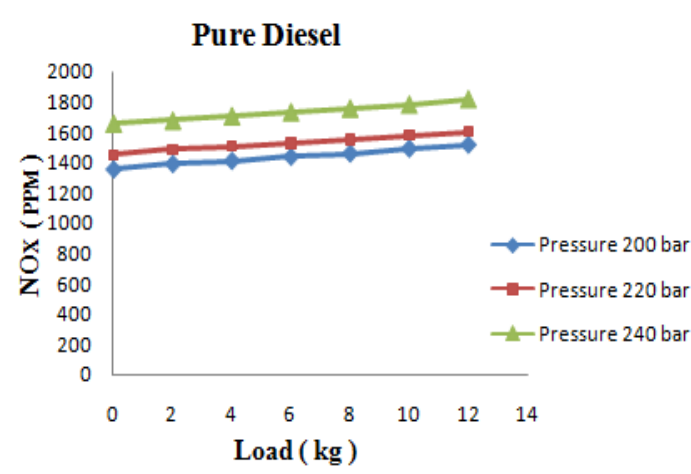

( a )

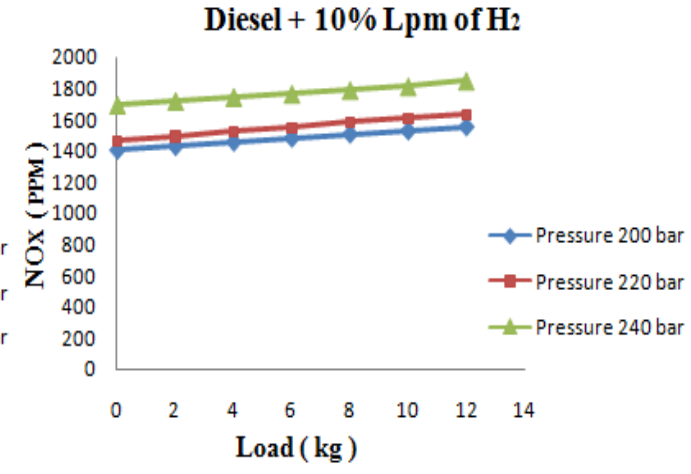

( b ) 


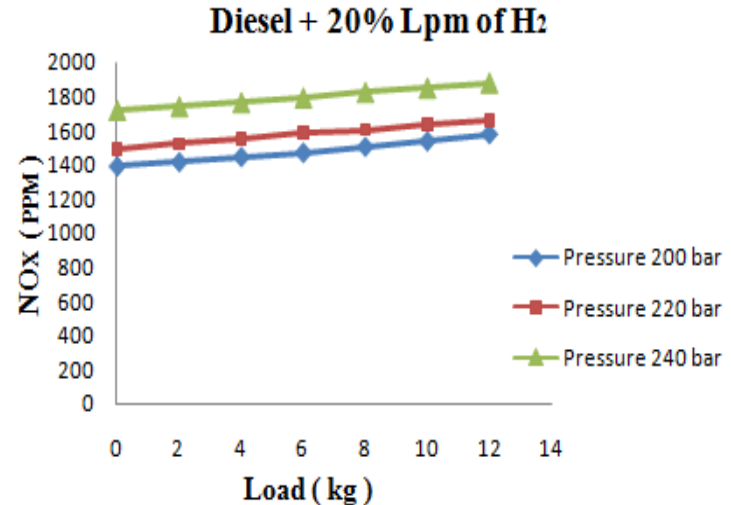

(c)

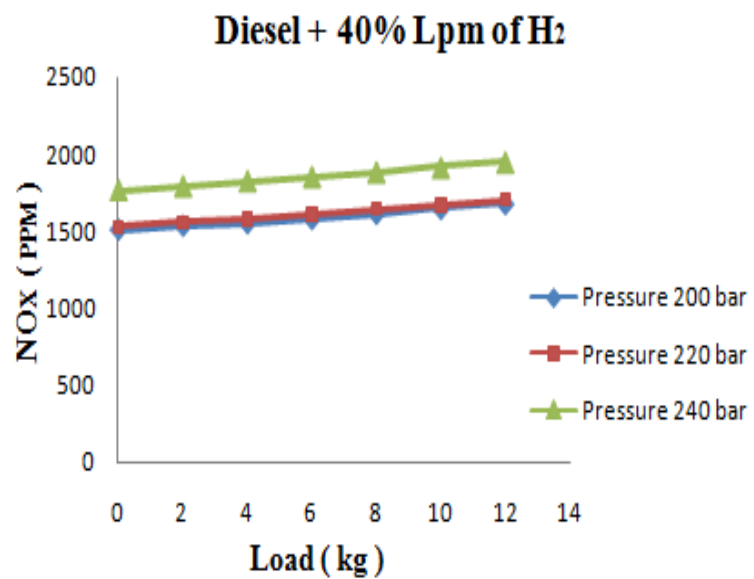

(e)

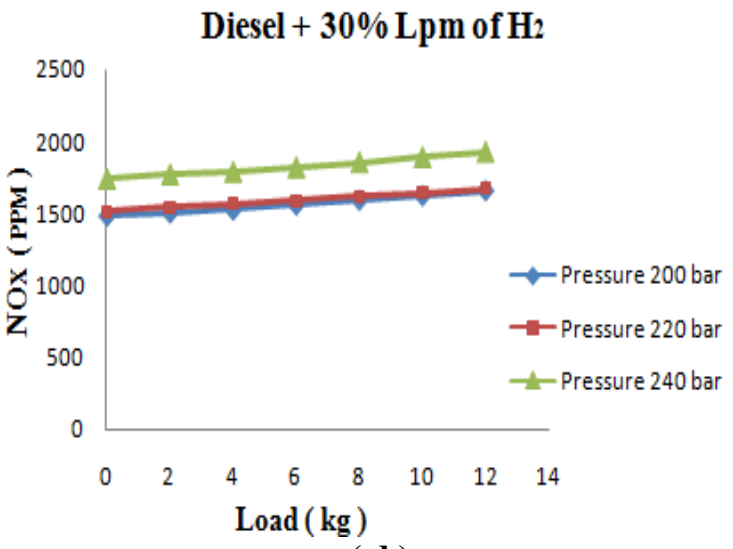

(d)

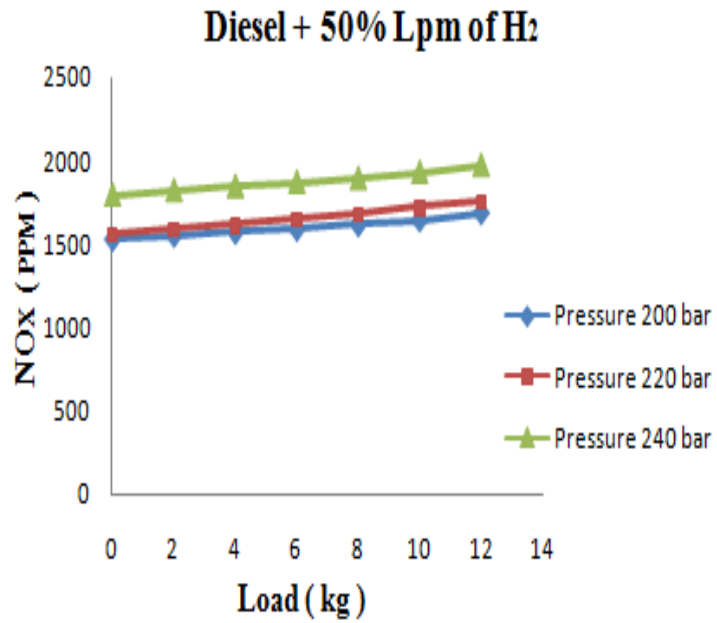

(f)

Figure 5: Relation between Load and $\mathrm{NO}_{\mathrm{X}}$ in PPM for different $\mathrm{LPM}$ of $\mathrm{H}_{2}$ at Various Pressures.

The Figure.6 indicates the connection between the load and the $\mathrm{O}_{2} \%$ at varying pressures. The level of oxygen decrease because of oxygen blended in with the $\mathrm{CO}$, and Nitrogen can form $\mathrm{CO}_{2}$ and Oxides of Nitrogen $\left(\mathrm{NO}_{\mathrm{x}}\right)$

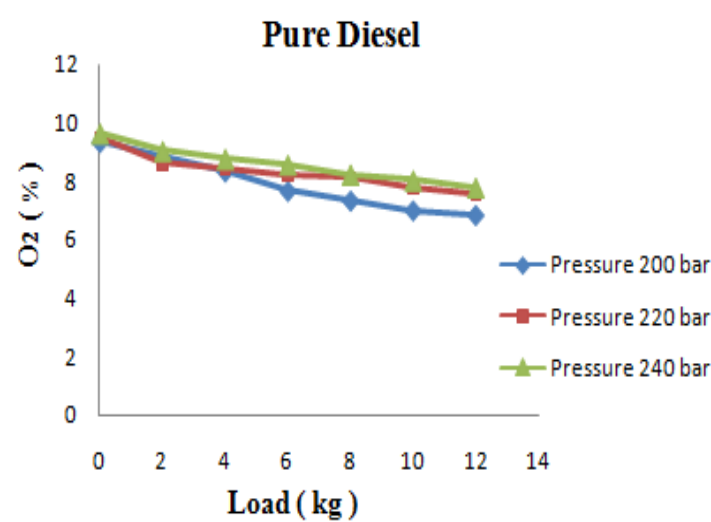

( a )

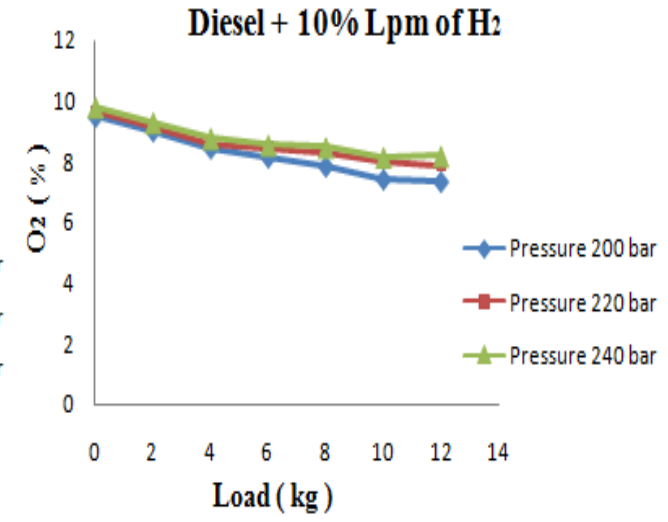

( b ) 


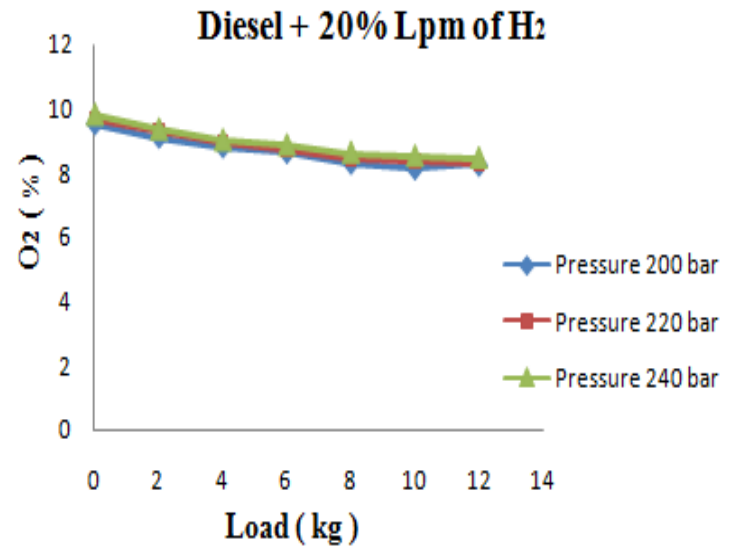

( c)

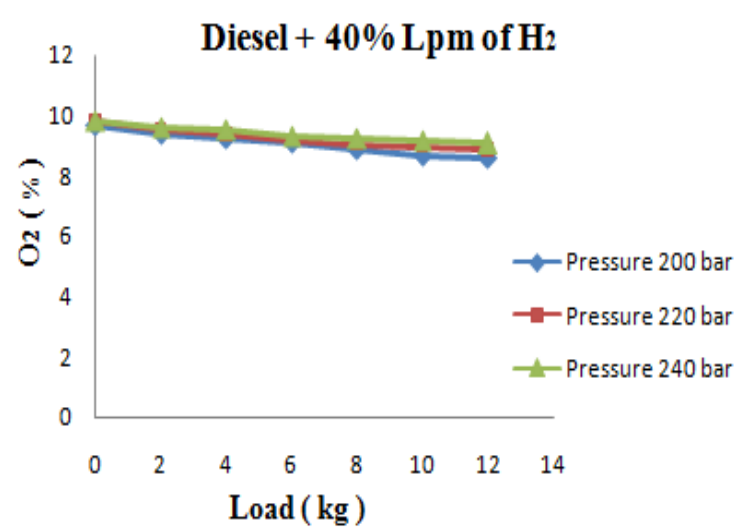

( e )

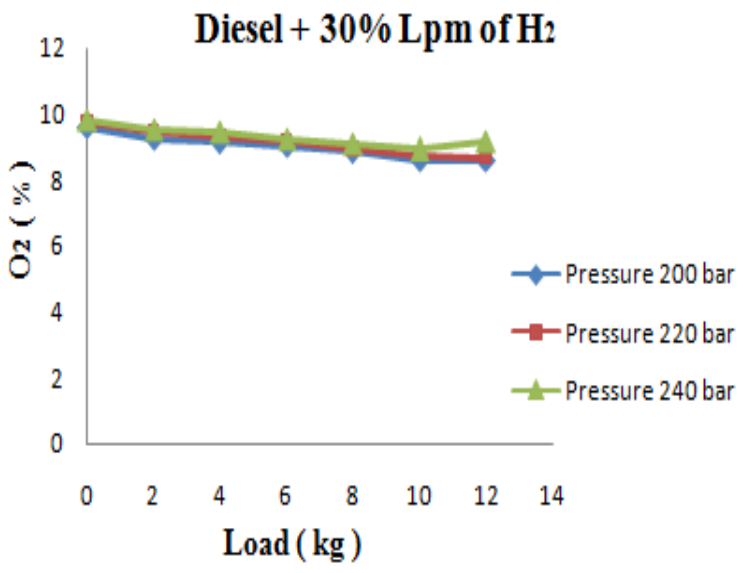

(d)

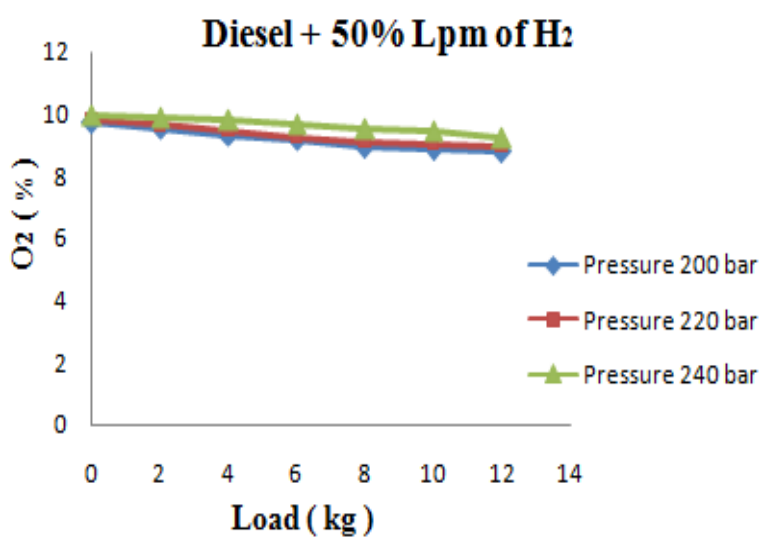

(f)

Figure 6: Relation between Load and $\mathrm{O}_{2} \%$ for different $\mathrm{LPM}$ of $\mathrm{H}_{2}$ at Various Pressures

\section{CONCLUSIONS}

In this analysis, samples were then taken of mixtures of hydrogen ratios integrated for testing on a single cylinder engine model and the necessary combustion, output and emission tests were obtained. Supply of hydrogen to the test engine by $10 \%, 20 \%, 30 \%, 40 \%$ and $50 \%$ of the overall load capacity reveals a massive reduction in smoke emissions and, at the same time, a dramatic increase in nitrogen oxides is observed. For an expansion in hydrogen content, there is a little increment in generally unburned hydrocarbons, despite the fact that $\mathrm{CO}_{2}$ and $\mathrm{CO}$ gas emissions have been essentially decreased. It was also found that, due to the addition of hydrogen to diesel fuel, the highest values were achieved by the incylinder gas pressure and the rate of heat release

\section{REFERENCES}

1. T S Hora and A K Agarwal "Effect of varying compression ratio on combustion performance and emission of Hydrogen Enriched Compressed Natural Gas (HECNG) fuelled engine JNGSAE Volume 31,PP: 819-828, 2016.

2. Yasin Karago'z, Tarkan Sandalcı, Levent Yuksek, Ahmet Selim Dalkılıcx and Somchai

3. Wongwises, "Effect of hydrogen-diesel dual-fuel usage on performance, emissions and diesel combustion in diesel engines" Advances in Mechanical Engineering, Vol. 8(8), PP: 1-13, 2016.

4. Rani, G. Jamuna, K. Srinivasa Rao, And Y. Goutham Raj. "Effect Of Hydrogen Enrichment On The Performance And Emissions of A Diesel Enginefueled With Mahua-Biodiesel." International Journal of Mechanical and Production 
Engineering Research and Development (IJMPERD) 9, Dec 2019, 126-133

5. RajsekherS.Hosmath,NagarajR.Banapurmath, "Performance, Emission and combustion Characteristics of Dual Fuel Engine Fuelled with Hydrogen Induction and Injection of Honne and Honage Methyl Esters" Energy and Power Engineering,7,PP 384-395August2015,

6. Yang, Z., Chu, C., Wang. L., \& Huang. Y. "Effects of $\mathrm{H}_{2}$ addition on combustion and exhaust emissions in a diesel engine". Elsevier Fuel, 139. PP: 190-197. January 2015.

7. Shingane, S., Et Al. "The Electrolysis Of Water To Generate Hydrogen (Hho) And A Study Of The Effect Of Addition Of Hho To Gasoline As An Engine Performance Improver." International Journal of Mechanical and Production Engineering Research and Development (IJMPERD) 8. 8, Oct 2018, 181-186

8. Yadav Vinod Singh, S.L.Soni, and Dilip Sharma, "Engine performance of optimized, hydrogen-fueled direct injection engine." Elsevier Energy 65PP: 116-122. 2014

9. Fonoschristodolou,AthanasionMegraities,n "Experimental investigation of the effects of separate hydrogen and nitrogen addition on the emission and combustion of a diesel engine" International Journal of Hydrogen energy Volume 38, Issue 24,PP:9945-10156,12 August 2013.

10. Ravichandran, T., M. Nagappan, And R. Arunraj. "Experimental Study Of Performance And Emission Characteristics Of A Single Cylinder Diesel Engine Using Karanja Biodiesel And Diesel Blends." International Journal of Mechanical and Production Engineering Research and Development (IJMPERD) 8. 4, Aug 2018, 677-684

11. Wu, Horng-Wen, and Zhan-Yi Wu. "Investigation on combustion characteristics and emissions of diesel-hydrogen mixtures by using energy-share method in a diesel engine". Applied Thermal Engineering 42,PP: 154-162, 2012

12. Shahad, Haroun AK, and Nabeel Abdul-Hadi. "Experimental Investigation of the Effect of Hydrogen Manifold Injection on the Performance of Compression Ignition Engines". World Academy of Science, Engineering and Technology 76, PP: 277ᄀ282, 2011

13. Kumar, S. Narasimha. "Comparative Study of Performance, Combustion and Exhaust Emissions Analysis of Linseed Oil Based Biodiesel in a Ceramic Coated Diesel Engine." International Journal of Mechanical and Production Engineering Research and Development (IJMPERD), 4 (2), 7598 (2014).

14. N.Saravanan,G.Nagarajan,C.Dhanusekaren,K.M.Kalaiselven,"Experimental Investigation of Hydrogen port fuel injection in DI diesel engine", International Journal of Energy and Environment Volume 1,Issue 2,PP:221- 248, 2010.

15. J M Gomes Antunes, R.Mikalsn, A.P.Roskilly, "An experimental study of a direct injection compression ignition hydrogen engine” International Journal of Hydrogen Energy, Volume 34,PP: 6516-6522, 2009.

\section{AUTHORS PROFILE}

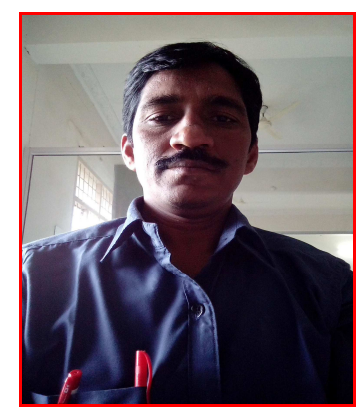

Mr. Y. Dilip Kumar, currently working as an Associate Professor in Mallareddy college of Engineering and Technology 
(MRCET). He had more than 20 years of teaching and research experience. He guided more than 100 students at graduation level and 30 students at post graduation level. He published 20 journals in various National and International journals. Present, He is perusing his doctoral degree from Jawaharlal Nehru Technological University, Anantapuramu. Andhra Pradesh.

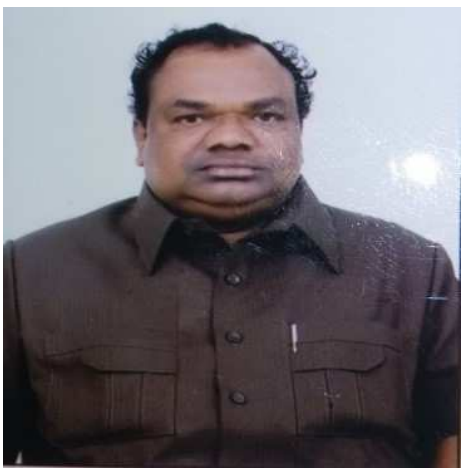

Dr. M. Yohan is a Professor in the Department of Mechanical Engineering, Jawaharlal Nehru Technological University, Anantapuramu, Andhra Pradesh. He published more than 30 journals in various International and National Journals. Professor M. Yohan serving at distinct capacities of administration from past 30 years at department and university levels with reliability and success. At present 10 member are perusing their doctoral degrees under the esteemed guidance of him. He is a recipient of BEST CITIZEN OF INDIA in the year of 2001 and recognised as a good Social service member from Red Cross Society of India. 

